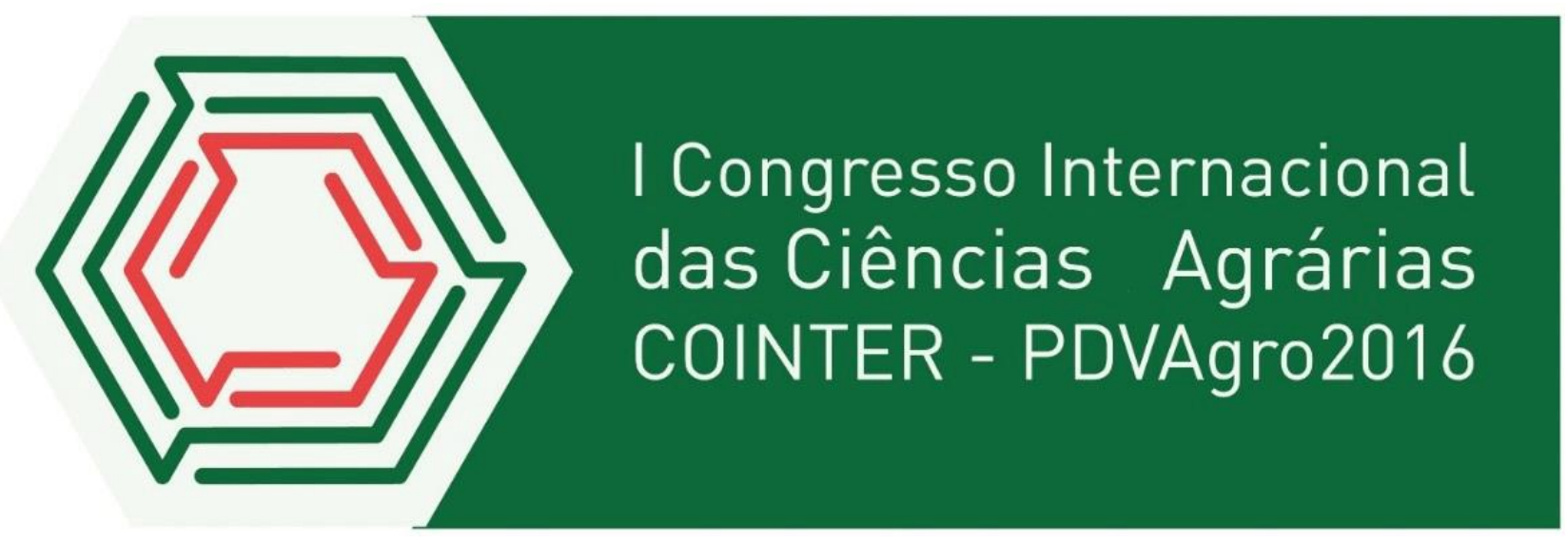

\title{
PRODUÇÃO DE BIOMASSA E EFICIÊNCIA DE UTILIZAÇÃO DE MACRONUTRIENTES PRIMÁRIOS POR VARIEDADES DE CANA NO PRIMEIRO CICLO
}

Apresentação: Pôster

Stella Jorge de Carvalho Neta ${ }^{1}$; Vinicius Santos Gomes da Silva²; Pablo Acácio dos Santos Souza ${ }^{3}$; Cíntia Caroline Gouveia da Silva ${ }^{4}$; Andressa Silva de Oliveira ${ }^{5}$

\section{Introdução}

Atualmente o setor canavieiro enfrenta uma crise agrícola (redução na produtividade) e industrial (fechamento de usinas). Assim pesquisas na canavicultura são necessárias para elevar o rendimento da cultura e torná-la mais competitiva (Cruz et al, 2013). Estudos têm recomendado que diversas práticas agrícolas como a calagem, gessagem, adubação química, adubação verde, uso de composto orgânico e adubação verde, contribuam para aumentar a produtividade da cana-de-açúcar (Rocha et al., 2008, Oliveira et al., 2011, Calheiros et al., 2012). Outra prática de grande importância para o sucesso da lavoura canavieira é a escolha de variedades de cana-de-açúcar com maior eficiência nutricional e produtiva que sejam adaptadas a diferentes ambientes edafoclimáticos.

Ante o exposto, objetivou-se com este trabalho avaliar a produção de biomassa e a eficiência da utilização de nutrientes por variedades de cana-de-açúcar, que representam mais de 50\% da lavoura canavieira de Alagoas, no ciclo de cana-planta.

\section{Fundamentação Teórica}

A exigência nutricional de uma cultura refere-se às quantidades de macro e micronutrientes que a planta retira do solo, adubo, e do ar, para atender suas necessidades e completar seu ciclo de vida. Essas informações são de fundamental importância para um manejo racional da cultura pois indicam as quantidades de nutrientes que devem ser fornecidos a cultura (Calheiros et al., 2012).

\footnotetext{
${ }_{1}^{1}$ Graduanda em Agronomia, Universidade Federal Rural de Pernambuco; stellajcarvalho@gmail.com

2 Doutorando em Ciências do Solo, Universidade Federal Rural de Pernambuco; vinicius.agro2008.1@gmail.com

${ }^{3}$ Graduando em Ciências Biológicas, Universidade Federal Rural de Pernambuco; pabloacacio@gmail.com

${ }^{4}$ Graduanda em Ciências Biológicas, Universidade Federal Rural de Pernambuco; cintia_stilo@hotmail.com

${ }^{5}$ Graduanda em Ciências Biológicas, Universidade Federal Rural de Pernambuco; andressasilvabio@outlook.com
} 
Devido sua elevada produção de biomassa, a cana retira do solo e aloca na planta uma grande quantidade de nutrientes. Para uma produção de 120 toneladas de matéria natural por hectare, cerca de 100 toneladas de colmos industrializáveis, o acúmulo de nutrientes na biomassa da parte aérea 150, 40, 180, 90, 50 e $40 \mathrm{~kg}$ de nitrogênio $(\mathrm{N})$, fósforo $(\mathrm{P})$, potássio $(\mathrm{K})$, cálcio $(\mathrm{Ca})$, magnésio $(\mathrm{Mg})$ e enxofre (S) é da ordem de 150. Em relação aos micronutrientes, a quantidade extraída é de $300 \mathrm{~g}$ de B, $270 \mathrm{~g}$ de $\mathrm{Cu} ; 8.900 \mathrm{~g}$ de Fe; $5.700 \mathrm{~g}$ de $\mathrm{Mn}$ e $720 \mathrm{~g}$ de Zn (OLIVEIRA et al.2007)..

Estudos têm demonstrado que as variedades podem apresentar diferenças na absorção e utilização de nutrientes (Oliveira et al., 2010; Kist et al., 2015). Desse modo, trabalhos que avaliam a eficiência nutricional são de grande importância, por possibilitar a escolha de variedades mais eficientes, reduzindo os custos de produção.

\section{Metodologia}

O estudo foi conduzido na Fazenda Jequiá, no município de Anadia, agreste Alagoano (Latitude $09^{\circ} 41^{\prime} 04^{\prime}$ 'S e Longitude $36^{\circ} 18^{\prime} 15^{\prime \prime} \mathrm{W}$ ). O solo da área experimental foi classificado como Latossolo Amarelo distrófico, de textura média, cuja caracterização química foi realizada em amostras de solo coletadas nas camadas $0,0-0,2 \mathrm{~m} ; 0,2-0,4 \mathrm{~m}$. Realizou-se a correção da acidez do solo utilizando calcário dolomítico, calculado pelo método que visa a elevação da saturação por base para 60\%, conforme Oliveira et al. (2007). Após a aplicação do calcário o solo foi arado e gradeado e em seguida realizou-se a abertura dos sulcos. A densidade de plantio oscilou em torno de 15 a 18 gemas por metro de sulco.

O delineamento experimental utilizado foi o de blocos ao acaso, com cinco repetições, constituídos por quatro variedades de cana-de-açúcar: SP813250, RB867515, RB92579 e VAT90212 cultivadas em parcelas de seis sulcos de 10,0 metros de comprimento, espaçados de 1,0 metro, totalizando $60 \mathrm{~m}^{2}$ de área total. Considerou-se área útil de cada parcela, as quatro linhas centrais com seis metros de comprimento, perfazendo $24 \mathrm{~m}^{2}$.

A adubação do solo foi baseada na recomendação da Usina Triunfo, conforme os resultados da análise de solo, aplicando-se 60, 100 e $150 \mathrm{~kg} \mathrm{ha}^{-1}$ de N, $\mathrm{P}_{2} \mathrm{O}_{5}$ e $\mathrm{K}_{2} \mathrm{O}$ aplicados no fundo do sulco. Por ocasião de maturação, 14 meses após o plantio, procedeu-se a colheita da cana em uma área de $2 \mathrm{~m}^{2}$ de cada parcela, cortando-se as plantas ao nível solo, mantendo-se as folhas verdes, secas, ponteiros e colmos. Em seguida as plantas foram pesadas determinando-se a biomassa total, essas informações foram utilizadas para a estimativa da produtividade de biomassa fresca (PBFPA t ha ${ }^{-1}$ ) conforme metodologia de Kist et al. (2015).

O acúmulo de nitrogênio, fósforo e potássio, foi obtido pelo teor de nutrientes determinado de 
acordo com Malavolta et al. (1997), multiplicado pelo acúmulo de matéria seca. A eficiência do uso de macronutrientes primários foi estimada por meio de expressão apresentada por Kist et al. (2015), em que a Eficiência de uso = produtividade de biomassa seca da parte aérea $\left(\mathrm{kg} \mathrm{ha}^{-1}\right)$ /acúmulo do nutriente na biomassa seca $\left(\mathrm{kg} \mathrm{ha}^{-1}\right)$. As análises estatísticas foram realizadas com o programa computacional Sisvar (Ferreira, 2008). As variáveis foram submetidas à análise de variância pelo Teste F. Para aquelas em que o F foi significativo, compararam-se as médias pelo Teste de Scott Knott a $5 \%$ de probabilidade.

\section{Resultados e Discussões}

As variedades de cana-de-açúcar não diferiram estatisticamente para a produtividade de biomassa seca da parte aérea (Figura 1). Esta produtividade pode ser considerada de média a alta para o Estado de Alagoas, onde a fase de crescimento máximo da cana ocorre em dias curtos e, portanto, sob baixa luminosidade, diferentemente do Centro-Sul do Brasil, onde o aumento da luminosidade coincide com a maior disponibilidade hídrica (Oliveira et al., 2011). A não coincidência da máxima disponibilidade hídrica com a luminosidade influencia negativamente, causando menor produtividade da cana-de-açúcar em Alagoas, quando comparada ao Centro-Sul do país (Oliveira et al., 2007).

Figura 1. Produtividade de biomassa seca da parte aérea de quatro variedades de cana-de-açúcar nos ciclos de canaplanta. Fonte: Própria

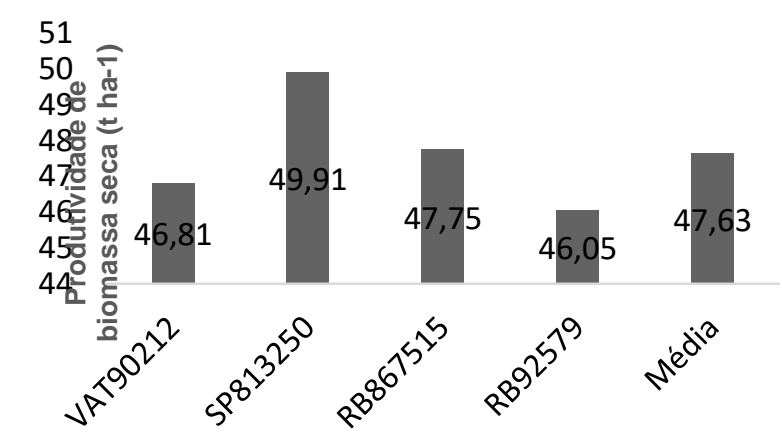

$\mathrm{Na}$ análise estatística do acúmulo de nitrogênio, fósforo e potássio não foram constatados efeito de variedades (Tabela 1). Os valores médios do acúmulo de macronutrientes primários na biomassa da parte aérea foram, em média, 182, 27 e $219 \mathrm{~kg} \mathrm{ha}^{-1}$ de $\mathrm{N}, \mathrm{P}, \mathrm{K}$ respectivamente. O que condicionou a seguinte ordem de extração: $K>N>P$.

Tabela 1. Valores médios para acúmulo de nitrogênio, fósforo e potássio em quatro variedades de cana-de- açúcar no ciclo de cana-planta. Fonte: Própria

\begin{tabular}{cccc}
\hline Variedade & Nitrogênio & Fósforo & Potássio \\
\hline RB867515 & $---------------k g ~ h a{ }^{-1}-$---------- & \\
\hline 176 a & 29 a & $221 \mathrm{a}$ \\
\hline
\end{tabular}




\begin{tabular}{llll}
\hline RB92579 & $177 \mathrm{a}$ & $26 \mathrm{a}$ & $216 \mathrm{a}$ \\
\hline SP813250 & $190 \mathrm{a}$ & $31 \mathrm{a}$ & $243 \mathrm{a}$ \\
\hline VAT90212 & $183 \mathrm{a}$ & $24 \mathrm{a}$ & $198 \mathrm{a}$ \\
\hline Média Geral & 182 & 27 & 219 \\
\hline C.V (\%) & 14,8 & 21,1 & 10,8 \\
\hline
\end{tabular}

Médias seguidas pela mesma letra não diferem entre si pelo Teste de Scott Knott a 5\% de probabilidade.

O acúmulo médio de nitrogênio foi semelhante ao obtido por Oliveira et al., (2011) que obtiveram $179 \mathrm{~kg} \mathrm{ha}^{-1}$, e superior 24\% ao verificado por Kist et al. (2015) que constatou $137 \mathrm{~kg} \mathrm{ha}^{-1}$. Em estudos conduzidos na zona da mata alagoana, verificou-se para o ciclo de cana-planta das variedades RB867515 e RB92579 tiveram a mesma capacidade de absorção de nutrientes e, o acúmulo de nitrogênio na biomassa da parte aérea da RB867515 e RB92579 foi da ordem de 220 kg ha $^{-1}$ (Calheiros et al., 2012), cerca de $20 \%$ maior que o do presente estudo.

O acúmulo de $\mathrm{P}$ na variedade RB92579 foi semelhante ao valor observado em estudos conduzidos por Calheiros et al. (2012) onde foi observada uma remoção de $25 \mathrm{~kg} \mathrm{ha}^{-1}$ pela RB867515, sendo superior ao valor observado por Oliveira et al. (2010), que obtiveram em seu estudo uma remoção de $19 \mathrm{~kg} \mathrm{ha}^{-1}$. Ao que diz respeito ao $\mathrm{K}$ na biomassa, constatou-se um acúmulo médio próximo ao observado por Oliveira et al. (2014) em estudo conduzido na Serra dos Aimorés/MG, onde os autores verificaram para a RB867515 e RB92579 um acúmulo médio de K de $221 \mathrm{~kg} \mathrm{ha}^{-1}$.

Os dados referentes à eficiência de utilização do N, P e K para produção de biomassa seca da parte aérea encontram-se na tabela 3. Observa-se que as cultivares comportaram-se de maneira semelhante, não diferindo estatisticamente entre si, apresentando uma eficiência média de 0,26, 1,70 e 0,21 t de biomassa para cada quilograma de nitrogênio, fósforo e potássio acumulado.

Tabela 2. Eficiência de utilização de nitrogênio, fósforo e potássio por quatro variedades de cana-de- açúcar no ciclo de cana-planta. Fonte: Própria

\begin{tabular}{cccc}
\hline Variedade & Nitrogênio & Fósforo & Potássio \\
\hline RB867515 & $0,26 \mathrm{a}$ & -exigência do nutriente/1 tonelada de MS- & $0,22 \mathrm{a}$ \\
\hline RB92579 & $0,27 \mathrm{a}$ & $1,70 \mathrm{a}$ & $0,21 \mathrm{a}$ \\
\hline SP813250 & $0,26 \mathrm{a}$ & $1,84 \mathrm{a}$ & $0,20 \mathrm{a}$ \\
\hline VAT90212 & $0,26 \mathrm{a}$ & $1,60 \mathrm{a}$ & $0,23 \mathrm{a}$ \\
\hline Média Geral & 0,26 & $1,96 \mathrm{a}$ & 0,21 \\
\hline C.V (\%) & 12,6 & 1,70 & 12,6 \\
\hline
\end{tabular}

Médias seguidas pela mesma letra não diferem entre si pelo Teste de Scott Knott a 5\% de probabilidade.

Em estudo para avaliação da eficiência do uso de nutrientes por 8 variedades de cana-deaçúcar Kist et al. (2015) observaram uma eficiência de 0,28; 0,96 e 0,15, para nitrogênio, fósforo e potássio, respectivamente. 


\section{Conclusões}

As variedades RB867515, RB92579, SP813250 e VAT90212 apresentaram produtividade de biomassa e acúmulo de nitrogênio, fósforo e potássio semelhantes.

Não foi possível identificar as cultivares mais produtivas apenas com base na eficiência de utilização nutricional, pois as variedades foram semelhantes na eficiência de uso dos nutrientes avaliados.

\section{Referências}

CALHEIROS, A. S.; OLIVEIRA, M. W.; FERREIRA, V. M. et al. Produção de biomassa, de açúcar e de proteína em função de variedades de cana e de adubação fosfatada. Semina: Ciências Agrárias, 33:. 809-818, 2012

CRUZ, A.; INÁCIO, R. A. C., MORAES, R. (2013). A crise no setor sucroenergético e as empresas do município de Sertãozinho-SP. Revista Eletrônica Diálogos Acadêmicos. 5: 114-127, 2013.

FERREIRA, D. F. SISVAR: um programa para análises e ensino de estatística. Revista Symposium, 6: 36-41, 2008.

KIST, V.; SILVEIRA, G., ALMEIDA, P. M. et al. Nutrient use efficiency in sugarcane cultivars. Científica, 43:117-125, 2015.

MALAVOLTA, E.; VITTI, G, C.; OLIVEIRA, A, S. et al. Avaliação do estado nutricional das plantas: Princípios e aplicações. Piracicaba POTAFOS. 1997. 319p.

OLIVEIRA, E.C.A.; FREIRE, F.J.; OLIVEIRA, R.I. et al. Extração de nutrientes por variedades de cana-de-açúcar cultivadas sob irrigação plena. Revista Brasileira de Ciência do Solo, 34:1343$1352,2010$.

OLIVEIRA, M. W., DA SILVA, V. S. G., REIS, L. S. et al. Produção e qualidade de três variedades de cana-de-açúcar cultivadas no Nordeste de Minas Gerais. Revista Ciência Agrícola, 12: 17-20, 2014.

OLIVEIRA, M. W.; FREIRE, F. M.; MACÊDO, G. A. R.; et al. Nutrição mineral e adubação da cana-de-açúcar.: Informe Agropecuário, 28:.30-43, 2007.

OLIVEIRA, M. W.; MAGRINI, J. L.; LYRA, F. E. V. et al. Produção da RB867515 influenciada pela aplicação de substâncias húmicas, aminoácidos e extrato de algas marinhas. STAB Açúcar, Álcool e Subprodutos 30:30-33, 2011.

ROCHA, A. T.; OLIVEIRA, A. C.; RODRIGUES, Á. N. et al. Emprego do gesso do Araripe na melhoria do ambiente radicular da cana-de-açúcar. Revista Brasileira de Ciências Agrárias, 3: 307-312, 2008. 